\title{
Objeto Infoestético “É um Livro”: do real ao virtual
}

\author{
Luciane Cuervo ${ }^{1,3}$ \\ Fabrícia Damando ${ }^{2,3}$ \\ Renata C. S. Bonotto ${ }^{3}$ \\ ${ }^{1}$ Departamento de Música - Universidade Federal do Rio Grande do Sul \\ ${ }^{2}$ Engenharia da Computação - Universidade Estadual do Rio Grande do Sul \\ 3 Programa de Pós-Graduação em Informática na Educação/UFRGS
}

\section{RESUMO}

Esse trabalho fundamentou-se nos estudos sobre redes de transformação e de subjetividade e sobre as tensões entre os conceitos de real e virtual. Um objeto infoestético e um vernissage foram preparados para subsidiar as reflexões. O objeto infoestético foi construído a partir da transposição de um livro impresso para o formato digital em vídeo. Nessa projeção, o alvo foi despertar sentimentos e sensações e também provocar paradoxos na intersecção entre o real e o virtual. A apresentação do objeto infoestético se deu no contexto de um vernissage de livros infanto-juvenis com uma ação artística explorando o tema da leitura, seus diferentes recursos tecnológicos, linguagens, gêneros, configurações e seus diferentes públicos. O vernissage proporcionou acesso e a manipulação de livros e materiais de diferentes configurações, formatos e propostas, incluindo ainda exemplos de integração do material impresso com mídias digitais. Conclui-se que longe de representar uma ameaça para o livro impresso, a tecnologia digital convive com ele, se alia e também se ressignifica em meio ao processo. A partir dessa experiência também se constata o potencial de propostas educacionais que incluem a elaboração e utilização de objetos infoestéticos.

Palavras-chave: Objeto infoestético; Virtual; Redes de transformação e subjetividade; Livros

\section{Info-Aesthetic Object "It is a Book": from real to virtual}

\begin{abstract}
This paper was based on studies on networks of transformation and subjectivity and on tensions between the concepts of reality and virtuality. An info-aesthetic object and a vernissage were prepared to subsidize those reflections. The info-aesthetic object represented a transposition from a printed book into video in digital format. In such projection, the target was to elicit feelings and sensations and also cause paradoxes at the intersection between the real and the virtual. The presentation of the infoaesthetic object took place in the context of a book vernissage with an artistic action exploring the theme of Reading, its different technological resources, languages, genres, settings and audience. The vernissage enabled access and manipulation of books and material with different configurations, shapes and proposals, including further instances of integration of printed materials with digital media materials. We conclude that far from representing a threat to the printed book, digital technology coexists with it, may serve as an ally and also signifies itself amid the whole process. From this experience, we also realize the potential of educational proposals that include the development and use of info-aesthetic objects.
\end{abstract}

Keywords: Info-aesthetic objects; Virtual; Digital Technology; Books. 


\section{INTRODUÇÃO}

A presente proposta tratou da transformação dos modos de leitura e interação com os livros, bem como dos diferentes materiais, recursos e espaços que os livros apresentam e ocupam hoje na sociedade.

Ao considerar o perfil interdisciplinar do grupo de trabalho, foi elencado como fio condutor da pesquisa o conjunto de experiências docentes em diferentes níveis de ensino, nas esferas pública e privada, permeadas e resignificadas pelo uso das tecnologias. O debate teve como ponto em comum as abordagens permeadas por diferentes tecnologias, seus usos e funções no processo educacional.

Após a apreciação de livros infanto-juvenis, o grupo decidiu aprofundar a análise e as reflexões sobre estudos a partir do livro "É um Livro", de Lane Smith. Inspirados nessa fábula, foi concebido um objeto infoestético constituído de elementos que apresentam e discutem fronteiras metafóricas entre o real e o virtual no que concerne aos livros. O real versus virtual, moderno versus antigo, conhecido versus desconhecido. A problemática do debate entre os personagens, aliada aos elementos e recursos visuais, ecoaram nas perspectivas e nas experiências das integrantes como educadoras, pesquisadoras, alunas, mães, interessadas tanto em livros quanto em tecnologia.

Dessa forma, surgiu a concepção estética do projeto “Vernissage É um Livro: do Real ao Virtual”. Nele foi criada a projeção do livro para o formato digital publicado na web, em formato de vídeo, com intuito de despertar sentimentos e sensações e também de provocar discussões sobre paradoxos na intersecção do real e o virtual. Consistiu, assim, em um processo de recriação do material original, partindo do livro "real” impresso e transformando-o em um objeto multimidiático dotado de som dos diálogos e efeitos, imagem em movimento e música. Dessa forma, o objeto infoestético englobou a apresentação por meio de um vernissage de livros infanto-juvenis e a produção de um vídeo animado e sonorizado do livro de Smith como o núcleo das discussões. A ação artística explorou esse tema, norteada pelas abordagens de diversos livros, em suas diferentes linguagens, suas configurações apresentadas nos mais distintos materiais e, portanto, seus diferentes públicos-alvo. O vernissage foi apresentado por ocasião do encerramento do Seminário Avançado “A estética das redes e o ciberespaço”, ministrado pela professora Maria Cristina Bizus, do Doutorado em Informática na Educação da UFRGS. A seguir serão apresentadas a fundamentação teórica que embasou o estudo e a produção, bem como os pressupostos basilares da concepção estética do trabalho.

\section{REFLEXÕES TEÓRICAS: DO REAL AO VIRTUAL}

A fundamentação da proposta deste trabalho está concentrada nas reflexões de Parente (2010) sobre as redes de transformação e a subjetividade. A partir das diversas leituras e discussões realizadas, percebese que a rede está envolvida em vários trabalhos teóricos e práticos de diversas áreas como a ciência, a educação, a tecnologia e a arte. Com base nessas ideias, arrisca-se afirmar que instaurou-se um novo paradigma. Aborda-se um pensamento das relações em oposição a um pensamento das essências.

Parente (2010) defende que o pensamento em redes está associado a pelo menos três temáticas gerais como a filosofia da rede, a rede como nova dimensão da comunicação e a estética da rede.

As redes são por demais reais... Elas sempre tiveram o poder de produção de subjetividade e do pensamento. Mas era como se as redes fossem dominadas por uma hierarquização social que nos impedia de pensar de forma rizomática. Como se ao se retirar, a hierarquização social deixasse ver não apenas uma pluralidade de pensamentos, mas o fato de que pensar é pensar em rede (Parente, 2010, p.91)

A subjetividade inerente às novas relações criadas no ambiente virtual vem recebendo novos olhares, articulados ao conceito de rede. 
Tanto o real como o virtual são dois conceitos complexos, os quais possuem diferentes significados conforme o contexto e época em que se aplicam. As definições encontradas em dicionários podem ser sintetizadas em duas linhas: o real como a realidade concreta ligada aos fatos; o virtual como algo potencial que se opõe ao real. Destacam-se duas abordagens:

Real: Que existe, que diz respeito às coisas, aos fatos. Oposto a fictício e imaginário, ilusório e aparente. Em um sentido metafísico, distingue-se o real, aquilo que existe por si mesmo, autonomamente, da ideia ou da representação que formamos dessa realidade (Japiassu, 2008).

Virtual: Que existe em potência e não em ato; suscetível de existir ou realizar-se, potencial. Da realidade de um computador de tudo que ocorre em um computador (Luft, 1999).

Por essas definições, depreende-se que o núcleo do conceito de real é a sua existência física e concreta, enquanto o virtual, em consonância ao contexto desse trabalho, poderia ser contextuali zado à esfera global sobre o que ocorre em, com e por meio de um computador - e é mediado, portanto, por diferentes tecnologias digitais, em tempos e espaços não necessariamente sincrônicos.

No entanto, pode-se questionar: até que ponto o virtual se opõe ao real?

O conceito de virtualidade foi discutido por Levy (1996), o qual refletiu sobre uma aparente oposição entre o real e o virtual. Sendo o virtual, em sua essência, algo em potencial a existir, mas contrário ao possível: "complexo problemático, o nó de tendências ou de forças que acompanha uma situação, um acontecimento, um objeto ou uma entidade qualquer, e que chama um processo de resolução, a atualização." (Levy, 1996, p.16). Enquanto isso, o real aproxima-se do que é possível, numa visão determinista, em que nada desvirtue de sua existência. Em suas palavras: "O possível é exatamente como o real, só lhe falta a existência.” (Levy, 1996, p. 16).

Nessa linha de pensamento, o virtual parece algo que gera certo conflito na criação, permeado pela imprevisibilidade, ao contrário da transição entre o possível e o real. Nesse sentido, o virtual surge como algo em potencial, com intrínseca força geradora.

Segundo Parente (s.d.), o virtual é um conceito repleto de definições e passível de discussões e, "ao contrário do que se pensa ele não remete a um além do real, mas ao próprio real”. Ou seja, por outro viés, o autor atrela o real e o virtual de modo instigante, pois aproxima ambos os conceitos de maneira tênue. Essa concepção pode ser relacionada ao contexto da informática educativa, cujo sentido da virtualidade muitas vezes é algo que, de fato, é "real", porém ocorre concretamente em diferentes tempos e espaços do mundo virtual.

A questão do tempo e do espaço é articulada ao conceito de virtualidade por Levy (1996), argumentando que a virtualização amplia esses limites. Para ele, novos modos de comunicação criam novas relações de tempo e espaço que também imbricam quem está fora desse sistema. Criam-se, assim, novas qualidades de histórias diferentes. Enquanto isso, Parente (1999) defende que, com relação ao virtual, há uma necessidade em ir além do real, que pode ser uma vontade de reconstituir o real, ou seja, o real enquanto novo.

O termo "realidade virtual” foi usado pela primeira vez no final dos anos 60 com o objetivo de designar um conjunto de tecnologias de visualização com a ajuda do computador. Essas tecnologias possibilitaram a criação do simulador de voo. Atualmente o termo "virtual”, portanto, compreende uma grande diversidade de conceitos, por isso faz-se necessário contextualizar esses conceitos de acordo com o enfoque das reflexões. 
Para algumas pessoas, segundo Parente (1999), a realidade virtual exprime a realidade na qual se vive e não se trata de pensar como a imagem representa a realidade, mas pensar um real em função do que a imagem permite visualizar.

No trabalho “Ambientes de Realidade Virtual e Educação: que Real é Este?” (Axt \& Schuch, 2001), discutem-se os ambientes de realidade virtual na educação, com enfoque do que é real e virtual. Vêm à tona problemáticas para reflexão interdisciplinar sobre o papel da educação, questionando-se como os alunos poderão lidar com tais realidades, desde uma perspectiva em que toda a interação acontece virtualmente até quais transformações essa transposição da vida em ambiente virtual poderão operar em modos de aprender-conhecer-sentir-comunicar. As pesquisadoras questionam como o sujeito que utiliza tecnologia, os ambientes de realidade virtual e as mídias interativas pode mergulhar em uma sensação de realidade, podendo ser "ilusória”. Uma das respostas é que a interação apresenta -se como fator importante, sendo que “dá ao sujeito uma sensação de estar no lugar proposto”, abrindo uma possibilidade ao sujeito, através da interação, de uma convicção da realidade.

É possível fazer uma analogia com o surgimento do livro na sociedade. Inicialmente, a cultura era oral. Com o surgimento da escrita, apareceram os primeiros registros, feitos em pedra e placas de argila, portanto, um legado "concreto" (real). Levou-se muito tempo para o livro tomar a diversidade de formas de hoje. E com a utilização das novas tecnologias ele continua em transformação. Se antigamente podiase ler os livros em forma de rolo como existe na Torah ${ }^{\mathrm{i}}$ até hoje, no computador, de certo modo, também se realiza a leitura como um rolo vertical, pois o texto sobe e desce na tela. Fazendo um paralelo à análise de vídeos como “Medieval Help Desk",ii, no qual dois monges do período medieval discutem uma nova tecnologia (o livro) frente à sua usual (pergaminho no sistema de rolo), percebe-se, neste caso, em tom cômico, a necessidade e o desafio que cada novo recurso exige. A divertida encenação mostra a resistência e o receio da pessoa com novas formas de interagir com um sistema que não lhe é inicialmente familiar e a necessária receptividade ao contato com novas tecnologias, o que, em princípio, a geração de nativos digitais do séc. 21 possui de maneira fluída no contexto urbano.

Uma questão instigante que engajou o desenvolvimento do presente trabalho surgiu no sentido de buscar ampliar o próprio conceito de virtual. Considerando que o virtual está em sintonia com elementos subjetivos muitas vezes não facilmente delineados, podemos expandir ao extremo o conceito de virtualidade, e chegar até a cognição em si. Como propõe Parente (2010):

Nós não cessamos de construir e re-construir modelos do mundo em nosso mente, usando os dados fornecidos pelos nossos órgãos dos sentidos e a capacidade de processamento de informações do nosso cérebro e das nossas linguagens. Habitualmente, pensamos no mundo como algo fora de nós, mas o que percebemos é fruto de modelos cognitivos que existem apenas em nosso cérebro.

Nesse sentido, seria a imaginação o limiar entre o real e o virtual?

Dubois (2004) apresentou algumas contribuições na reflexão sobre a fotografia, cinema, vídeo e o domínio digital, sendo que a evolução das máquinas atende a determinadas fases. Dentre elas, destacase, na quarta fase, a imagem, que agora pode ser transmitida ao vivo e para muitas pesso as em tempos e lugares diversos. Além dessas, o pesquisador ainda cita a imagem informática, chamada de imagem de síntese. Dessa forma o real torna-se maquínico, sendo gerado pelo computador, totalmente virtual.

No viés filosófico, Parente (1999) apresenta o conceito de Coleridge, que chamava de "fé poética”, onde a questão da auto-referência das novas tecnologias seria um fruto da disposição do espectador, sendo que toda arte produz no espectador uma espécie de ilusão referencial, que depende da "fé do espectador”. Algo que seja produzido pode representar com total realidade o que a imagem desse objeto 
apresenta. O vídeo, por exemplo, pode ser auto-referente, uma imagem da imagem. Assim, depreende-se que a auto-referência de um vídeo nem sempre é uma determinação técnica relativa a um meio de expressão, e que, ainda, depende-se da fé do espectador, sendo eu a imagem pode se dar um "duplo tão perfeito do real que a ele se substitui”.

Nesse ponto de vista, o vídeo desenvolvido sobre um livro real apresenta-se como virtual, mas um virtual que remete ao real. Trata-se da imagem auto-referente, podendo ser uma imagem da imagem na qual apresenta-se com uma realidade tão significante que tende a ser tão real quanto o livro impresso. Se depende da fé do espectador, da interação do sujeito com o meio e as apropriações advindas das experiências com o vídeo produzido, despertam-se e trabalham-se vários sentidos: visão e audição, além de possibilitar e desertar emoções de alegria, euforia e até mesmo a melancolia. De posse dessas emoções e através da consciência das mesmas, o sentimento pode tomar conta do espectador e, consequentemente, o levará a "fé poética”.

O paradoxo do real ao virtual não pode ser simplificado ao nível do que é concreto e do que é subjetivo, especialmente no mundo contemporâneo em que há verdadeiras "realidades paralelas" no ambiente virtual. Conforme explicam Axt \& Schuch (2001):

São outras realidades, cuja concretização traz no rastro questões de natureza epistemológica e ética, no âmbito de teorias que tratam do conhecimento e da subjetividade, e cujas respostas provisórias afetam/poderão afetar os encaminhamentos no campo educativo no seu sentido mais amplo.

Com o intuito de criar um produto físico suscitado por essas reflexões, o objetivo geral da presente proposta, assim, foi discutir os diferentes modos de abordagens e interações que os livros proporcionam, transcendendo a ideia convencional do que é um livro. Para isso, um conjunto de ações foi planejado, englobando a criação de um objeto infoestético composto por um vídeo e um vernissage.

\section{OBJETO INFOESTÉTICO}

Um objeto infoestético, para Manovich (2008), "refere-se às práticas culturais que podem ser melhor compreendidas como uma resposta às novas prioridades da sociedade da informação, trabal har com ela e produzir conhecimento a partir da informação". Por esse ponto de vista, acredita-se que o conjunto de ações multimídia e multissensoriais composto por um vernissage e um vídeo pode ser um objeto infoestético que atende a essa nova sociedade da informação, com novas interações, podendo inclusive despertar novos sentimentos e sensações o livro impresso convencional tem como fator limitante.

Manovich (2008) ressalta que a infoestética não obriga a usar o termo de nova mídia, mas, se para produzir algo, for necessário usar computador e softwares, são usadas algumas das novas mídias de fato. Ele ainda destaca que um projeto infoestético examina a cultura contemporânea para detectar estéticas emergentes e culturais de formas específicas da sociedade da informação, sendo assim, práticas culturais contemporâneas que podem ser mais bem compreendidas como respostas às novas necessidades da sociedade da informação. Nessa sociedade, há necessidade em dar sentido à informação, trabalhando com a informação para gerar conhecimento através de manifestações culturais, ecológicas, tecnológicas, ensejando ainda novas interações e produzindo subjetividade.

Se, por um lado, pretende-se obter o efeito proposto por Manovich (2008) com o objeto infoestético delineado como vídeo animado e sonorizado do livro impresso, considera-se ampliar seu alcance e transcender com a organização de um vernissage de livros infanto-juvenis em torno de uma ação artística explorando o tema da leitura, suas diferentes linguagens, configurações e públicos. 
A produção desencadeou a pesquisa e a produção foi o livro "É um Livro”. Essa publicação infantojuvenil apresenta uma fábula por meio do diálogo entre dois personagens que defendem seus modos de agir, aparentemente em um momento futuro hipotético em que o livro seria considerado um objeto antigo e, de tão obsoleto, passaria a ser um “artigo desconhecido”. A seguir a capa do livro (figura 1):

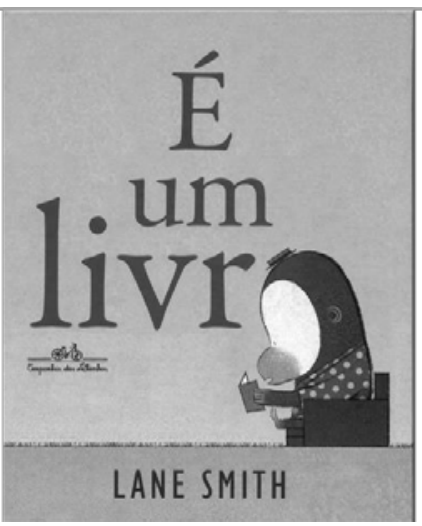

Figura 1. Livro que inspirou o desenvolvimento do objeto infoestético

Diante dos incríveis recursos tecnológicos disponíveis nesse contexto metafórico, a proposta de um (simples) livro supostamente não seria suficientemente atrativa e cativante. Enquanto um dos personagens, afeito às tecnologias digitais, manipula uma espécie de tablet, o outro lê um livro de aventura no formato convencional em papel. O inusitado diálogo começa despretensiosamente, com perguntas do sujeito High Tech do tipo - [Este livro] Possui login? - Twíta? - Como baixa a página?

As respostas curtas do personagem leitor (convencional) repetem-se em tom impaciente: “- Não. - É um livro”. A história se desenvolve para a conquista do personagem usuário virtual/digital pelo livro convencional, simbolizando de modo perspicaz a discussão entre o real e o virtual passível de discussões sobre a cibercultura e a leitura.

Cabe articular essa proposta às ideias de Levy (1996), o qual afirma que o texto é, por si só, uma entidade virtual e abstrata que sofre atualizações a cada leitura. Por essa perspectiva, novos vínculos são estabelecidos entre os mecanismos ligados à virtualização, no momento em que o texto desencadeia múltiplos sentidos em seus constantes vazios. Para ele, essa é a essência da ação da leitura: um processo de construção e desconstrução, que resulte num desdobramento de sentidos: "O espaço do sentido não preexiste à leitura. É ao percorrê-lo, ao cartografá-lo que o fabricamos, que o atualizamos” (Levy, 1996, p.36). Pode-se depreender desses pensamentos que o significado é gerado pelo leitor a cada leitura.

\subsection{Vídeo e vernissage}

Um vernissage é uma inauguração ou exibição social de uma ou mais obras e seus colaboradores. Dessa forma o Vernissage É um Livro apresentou um panorama de vários tipos de livros infanto-juvenis a partir do acervo pessoal das professoras-pesquisadoras. Foi fomentada, ainda a possibilidade da exploração multissensorial e interação dos/com os livros através dos cinco sentidos: visão, olfato, tato, paladar e audição.

Nessa produção foi concebida a edição e a projeção em natureza audiovisual do livro par a o formato digital publicado na web, em formato de vídeo, com intuito de instigar as rela ções entre o real e o virtual. Como trilha sonora, foi editada a obra musical "Variações sobre o Peixe Vivo" de Osvaldo 
Lacerda, recolhida na faixa original do CD “Octoeólio, Oito Ventos do Brasil Meridional” (CUERVO, 2006), mediante a autorização da diretora artística do trabalho.

No que se refere aos aspectos técnicos, o vídeo empregou ferramentas de edição de vídeo como o software Windows Movie Maker iii e edição de áudio com o software livre Audacity ${ }^{i v}$. Cabe registrar que a escolha por estes softwares deu-se pela acessibilidade deles, considerando que a proposta foi concebida para futura implementação em ambiente escolar. Essa produção contou com a captação de cada imagem e posterior sincronização das falas dos personagens que foram feitas por crianças, a fim de oferecer uma característica mais infantil ao vídeo. Houve inserção de imagens novas (de domínio público e acesso livre na internet) além do livro a fim de ilustrar termos, sentidos e conteúdos trazidos pelos diálogos dos personagens do livro, além de ter as vozes e apresentar legenda em todas as telas referentes às "páginas” do livro em vídeo, tornando-o mais sensível e acessível.

Desse modo, vias de comunicação alternativa foram possibilitadas através da oferta de estímulos sensoriais diversos proporcionados pelo vídeo elaborado: imagem, som, legenda e movimento. Esse foi outro aspecto que despertou interesse e atenção do grupo: a capacidade desse objeto infoest ético incorporar elementos que o tornem acessível a pessoas com deficiência. Para parte desse público, conforme as limitações de sua deficiência, o livro no formato impresso estabelece um limite à construção de sentido quando não acompanhado de recursos de acessibilidade.

Nessa projeção, o alvo é despertar novos sentimentos e sensações e também provocar paradoxos na intersecção de realidade e virtualidade. A estória do livro impresso, então, passa a ser contada de forma digital, através das imagens, dos sons, da música de fundo, de uma nova atmosfera construída bem como novos efeitos estético-visuais acrescidos às páginas. Nessa nova criação, reúnem-se as páginas do livro impresso assim como as páginas da tela do computador. Tudo isso é viabilizado pelo uso de ferramentas tecnológicas que estão ao nosso alcance.

O projeto utilizou, conforme Manovich (2008) aborda, novas mídias, além de trabalhar com uma nova forma de comunicação com a sociedade da informação, sociedade atual onde deu novo sentido à informação do livro, trouxe para a sociedade uma nova forma de apresentar um livro, permitindo explorar outros sentidos, como por exemplo a audição.

Na ocasião do Vernissage, foram reunidos, catalogados e expostos mais de 100 livros compostos de diferentes tamanhos, texturas, tecnologias e modos de interação. Foi possibilitado o manuseio e a interação com diversos livros infanto-juvenis, com materiais e formas distintos entre si, de texturas de pano, plástico, papel em diferentes gramaturas, madeira, dobraduras (tipo pop-up), acessórios como lupas, chocalhos e até livros comestíveis e recursos eletrônicos diversos. Ainda que o público presente fosse formado de pesquisadores adultos, o evento promoveu a ludicidade, a leveza e a interação prazerosa entre todos os presentes, na medida em que puderam experimentar enquanto leitores de todos esses livros tão diversos, com reações diversas na mesma proporção. Enquanto alguns livros remetiam nos à sua infância, outros surpreendiam pelas inusitadas formas analógicas ou digitais de interação.

A própria categorização que baseou a curadoria da exposição também precisou ser pensada e repensada à luz da fundamentação teórica, numa abordagem multissensorial. Questionamentos que envolviam materiais, modos de interação, recursos necessários, faixa etária, efeitos (visuais, sonoros, táteis, olfativos, degustativos) por recursos mecânicos ou eletrônicos. Foram apresentados livros que possibilitavam diferentes níveis de interação com a história, indo do simples ato de virar a página até a escolha do destino dos personagens por meio de roteiros alternativos. Os livros tinham predominantemente o idioma português, no entanto foram apresentados exemplares em inglês, espanhol, francês e alemão. Incluíam, ainda, recursos de natureza didática (para aprender a ler, a 
desenhar, a conhecer o corpo humano, etc), livros-brinquedo (de quebra-cabeça, corrida, de banho etc.), bem como livros interativos com manuseio através de Ipad e computador, com efeitos tridimensionais e de realidade aumentada. As fotos das figuras 2 e 3 apresentam alguns momentos no vernissage.

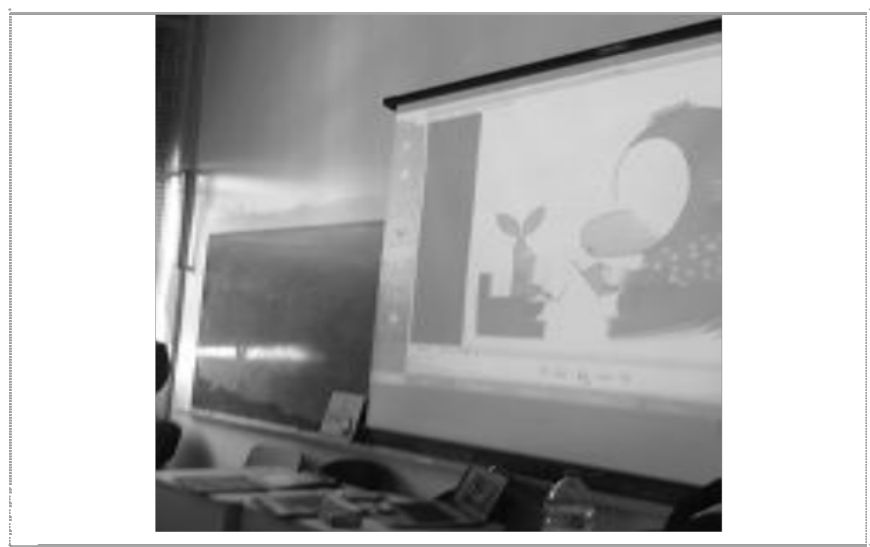

Figura 2. Apresentação do vídeo objeto infoestético

Para esse evento, também foi exposta uma produção concebida como “PIZZARAL”, desenvolvida pelos alunos da Escola Balão Vermelho (Porto Alegre/RS), utilizando o livro "Brincriar” (Camargo, 2007). Através da leitura da poesia "PIZZARAL", os alunos produziram obras de arte a partir da poesia durante a semana do livro da escola. PIZZARAL explora a história de Genaro que tinha um canteiro de pizzas, inclusive pizza virtual. Foram desenvolvidas desde o berçário até o jardim B árvores compostas por pizzas, cada pizza possuía elementos, ou melhor, ingredientes que os alunos criaram através de pinturas e desenhos. Apresentou, assim, a possibilidade de apresentar um objeto estético a partir da leitura de livro, construindo e recriando saberes junto aos alunos. A figura 3 mostra parte do PIZZARAL no vernissage.

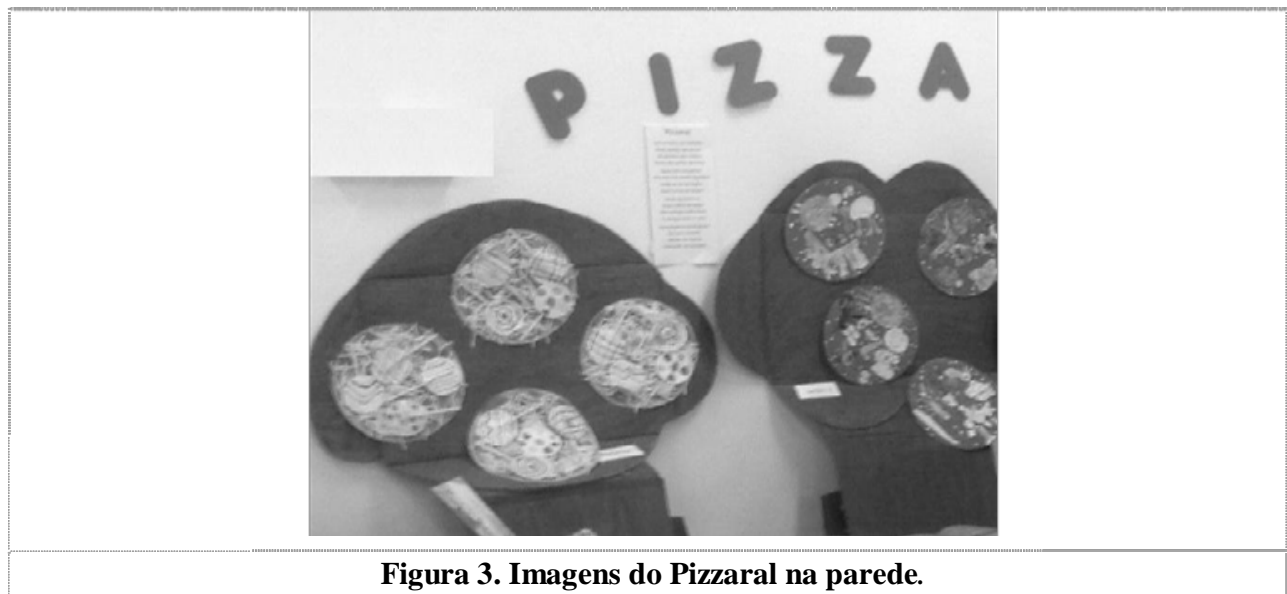

Nesse contexto, promoveu-se a desconstrução da visão restrita do livro impresso e suas possibilidades e ressaltou-se o caráter ubíquo do mesmo.

Por fim, com a apresentação geral do trabalho, foram discutidos os diferentes modos de abordagens e interações que os livros proporcionam atualmente, transcendendo o convencional de sua própria representação para além, enquanto também foi estabelecida uma gama de possibilidades e recursos tecnológicos. 
De forma alguma pretende-se com este trabalho mostrar que o texto, livro textual, impresso e encadernado em papel, será substituído por um vídeo sobre o livro, ou um livro totalmente interativo. Acredita-se que o livro impresso perdurará por muito tempo. Parente (1999) afirma que o texto impresso tende a se especializar de tal forma que encontrará modalidades propícias ao seu uso. Segundo o autor, em relação ao texto eletrônico, novas modalidades de produção e difusão do texto, diferentes das impressas. Sendo assim, não se têm a substituição de um pelo outro, pois o texto impresso não será, necessariamente, substituído pelo texto eletrônico.

O vídeo desenvolvido pode ser visualizado através do seguinte link: <https:/www.dropbox.com/s/qlq1ja2dz75ptfx/\%C3\%89\%20um\%20livro\%20final.mp4>.

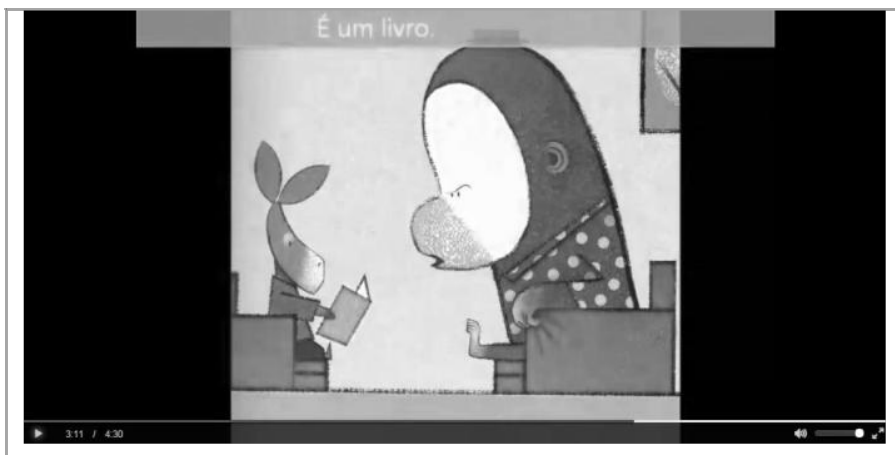

Figura 4. Imagem da tela do vídeo

\section{CONSIDERAÇÕES FINAIS}

O presente trabalho teve como objetivo desenvolver um objeto infoestético através da recriação da obra impressa de Lane Smith "É um Livro" para o formato de vídeo e a apresentação de um vernissage multissensorial.

A informação estética em formato de vídeo apresentado proporcionou inúmeras formas de comunicar ideias e produzir sentidos. Mesmo que nem todos compreendam uma determinada língua enquanto código escrito e/ou falado, a imagem, som, movimento e contexto integrado constituem meios de comunicação e ampliam as possibilidades de interpretação e produção de subjetividade.

A informação estética, além de provocar a emoção, pode também despertar nas pessoas o desafio de (re)construir o pensamento e experimentá-lo através de um conjunto de meios de expressão (Semeler \& Rozados, 2012). Integrar o objeto infoestético ao vernissage permitiu aprofundar ainda mais essa experiência.

Fica evidente que a tecnologia, longe de representar uma ameaça para o livro impresso, convive com ele, se alia e também se ressignifica em meio a todo o processo. Ao contrário de caminhar para a sua extinção, o livro não será totalmente substituído por vídeos ou outras formas que permitam interatividade ampliada. O livro impresso perdura e ele mesmo passa por alterações e hibridizações em novas formas, constituindo-se de um objeto que, por si só, transita entre o concreto e o imaginário, entre o real e o virtual.

Percebe-se que projetos dessa natureza possuem capacidade de fomentar novas formas de trabalhar a leitura com os alunos, articulando recursos analógicos e digitais num processo colaborativo, criativo e crítico. A metodologia pode empregar diferentes etapas da construção de uma pesquisa científica, sem deixar de lado a ludicidade, a curiosidade, o diálogo e o pensamento criativo. Tanto os contornos quanto 
os desdobramentos de propostas desse tipo são imensuráveis, bem como as ressonâncias que podem suscitar no ambiente escolar e acadêmico.

Apesar da equipe de pesquisa e produção ter acesso a softwares pagos, com recursos mais sofisticados do que os apresentados no vídeo realizado, optou-se por utilizar softwares livres, também com um olhar pedagógico no trabalho na escola. Assim, ainda que o vernissage tenha ocorrido num momento presente específico, o vídeo, de configuração simples e leve, torna-se acessível em tempos, lugares e máquinas distintos. E podem, também, inspirar projetos pedagógicos que visem valorizar e promover a reflexão do potencial educativo das tecnologias.

Em nossas atuações docentes em diferentes níveis de ensino, temos compartilha do o vídeo e o projeto como um todo, e os colegas têm mostrado uma excelente receptividade, refletindo também a acolhida pelos alunos. Essas experiências para além do ambiente acadêmico também denotam a demanda existente no ambiente escolar para projetos que utilizem as TIC de maneira contextualizada aos materiais escolares e recursos didáticos convencionais.

Como exposto no vernissage, o formato impresso especializou-se de tal forma a partir do século 20, que exibe muitas modalidades propícias ao seu uso. De modo semelhante, os produtos virtuais digitais se configuram a partir de novas e diferenciadas modalidades de produção, apresentação e representação bem como de difusão - essas são diferentes das impressas, mas igualmente legítimas.

\footnotetext{
${ }^{\text {i }}$ Principal livro religioso da cultura judaica, que está presente nas sinagogas.

ii Disponível em: <http://www.youtube.com/watch?v=4ZwJZNAU-hE>

iii Disponível para download: <http://windows.microsoft.com/pt-br/windows-live/movie-maker>

${ }^{\text {iv }}$ Disponível para download em: <http://audacity.sourceforge.net/?lang=pt-BR>
}

\section{REFERÊNCIAS}

AXT, M.; SCHUCH, E. M. M. Ambientes de Realidade Virtual e Educação: que Real é Este? Interface Comunicação, Saúde e Educação IX. Agosto de 2001.

CUERVO, L. Octoeólio, Os Oito Ventos do Sul Meridional. Octeto de Flautas Doces. Independente, 2006.

DILAN, C. Brincriar. Porto Alegre: Edutora Projeto, 2007.

DUBOIS, P. Cinema, vídeo, Godard. São Paulo: Cosac Naity, 2004.

JAPIASSU, H. Dicionário Básico de Filosofia. 5. ed. Rio de Janeiro: Zahar, 2008.

LEVY, P.; O Que é o Virtual, São Paulo, Editora 34, 1996. LUFT, C.

P. Minidicionário. 16. ed. São Paulo: Ática, 1999. MANOVICH, L.

Introducion a Info-Aesthetics. 2008. Disponível em:

http://manovich.net/Manovich.InfoAesthetics.2008.pdf. Acessado em 13.Julho. 2013.

PARENTE, A. (org.). Tramas da Rede: novas dimensões filosóficas, estéticas e políticas da comunicação. Porto Alegre: Sulina, 2010.

PARENTE, A. A Última Versão da Realidade. In:

$<$ http://souzaesilva.com/projects/webdesign/sitenucleoold/projetos/publica/artigos/andre.htm>

PARENTE, A. O Virtual e o Hipertextual. Rio de Janeiro: Pazulin,1999.

REVISTA CRESCER <http://revistacrescer.globo.com/Revista/Crescer/0,EMI237592-17759,00-

OS+MELHORES+LIVROS+INFANTIS.html> site da revista crescer com os melhores livros infantis.

SEMELER, A. R; ROZADOS, H. B. F.. Imagem, Informação e Tecnologia. Revista Informática e

Informação. Londrina, V17, n.1, p 78-92, 2012.

SMITH, L. É um livro. São Paulo: Companhia das Letrinhas, 2010. 